SUSANA MORENOS.

Arquitecta Universidad Europea de Madrid

MAX AGUIRRE G.

Arquitecto Universidad de Chile

\section{El giro de la intervención urbana}

$\mathrm{H}^{2}$ ay en curso, desde los años 90 del siglo pasado, un cambio de dirección de la intervención urbana. Ya no se trata de rehabilitación sino de regeneración urbana.

En el caso de España, Moreno y González, destacan la Carta de Toledo de 2010 como el documento de referencia donde se definió la regeneración urbana integrada como herramienta del nuevo giro de la intervención. Se trata ahora que la estrategia compatibilice la capacidad comercial con la vitalidad perdida de los centros históricos y se recualifiquen los espacios públicos y de equipamiento como recursos de la integración de la diversidad cultural en esos mismos centros. En los ya antiguos barrios periféricos del desarrollismo del siglo xx, la actualización va acompañada de rehabilitaciones bioclimáticas junto con, cuando corresponda, tratar la exclusión social desde la regeneración urbana. Se habla de un metabolismo urbano carbono cero, especialmente en los tejidos urbanos turísticos, recuperando mucha segunda vivienda con patologías debidas a la antigüedad de las construcciones e incorporando estándares actualizados de calidad turística y residencial. En definitiva, la intervención regeneradora de los tejidos urbanos de la ciudad consolidada se concreta en actuaciones de distinta naturaleza, la ciudad que resultó de la aplicación de modelos basados en la zonificación y segregación de usos, se dispone ahora a la regeneración en fragmentos urbanos que se ensayan a través del proyecto urbanístico piloto: polígonos de vivienda en las antiguas periferias, (barrios o barriadas), áreas de relleno o completamiento, áreas de transformación de usos o de nueva oportunidad (puertos, complejos industriales, áreas decaídas de oficinas), áreas de centralidad.

En Dinamarca, la experiencia ha permitido identificar cuatro estilos de planificación aplicados a la regeneración urbana: de inversión pública, planificación regulativa, planificación de tendencia y planificación de soporte. El factor común en todos ellos ha sido la necesidad de negociación de los distintos actores participantes desde sus respectivos intereses, diferenciándose en los diversos grados de intervención e influencia que ejerce la autoridad pública, los inversores y el mercado. El empleo de términos como los de gobernanza y liderazgo colaborativo se han hecho recurrentes en los procesos de negociación, que no siempre se han resuelto con la rapidez deseada y requerida, teniendo que esperar, en algunos casos, más de una década para que se alcance un acuerdo conducente a la realización de las transformaciones acordadas. El caso de Aalborg, expuesto por Galland, resulta relevante por las características adoptadas en su desarrollo, tratándose del malecón que ocupa la parte central del fiordo que bordea la ciudad, la intervención urbana se basó en un modelo "sitio por sitio", en el que la propiedad de la tierra, las condiciones del mercado y las políticas urbanas locales determinaron el carácter de los procesos regenerativos, denominando a esta "ola de regeneración: la ciudad creativa" porque se han previsto variados proyectos de arquitectura de índole cultural, espacios públicos y parques, yuxtapuestos con áreas residenciales y de comercio, logrando satisfacer los intereses de los involucrados, no sin arduos debates públicos, participación de residentes y negociaciones político-económicas.

El caso de Europarei, en Uithoorn (Holanda), presentado por Alonso y Aparicio, también se aboca a una intervención urbana mediante la recuperación de la calidad y vitalidad de un antiguo barrio de 
vivienda social de los años 60 , donde superado un primer intento de reestructuración que fracasó, habiendo tenido la participación de los habitantes del barrio, el ayuntamiento, la corporación administradora de los alquileres y la policía local, se intenta ahora un plan integral que comprende todos los campos (calidad de la vivienda, reducción de problemas sociales, mejoramiento de la vida social en el barrio y otros aspectos de la misma índole), pero a un plazo mayor que el contemplado en el primer intento. El riesgo que corre este plan radica en el largo plazo contemplado para su realización, dejando en la incertidumbre los efectos que sobre los objetivos propuestos puedan ejercer factores económicos y sociales que hoy se mueven con enorme dinamicidad. Esto hace prever que el modelo tendrá que estar preparado para ejercitar una flexibilidad y capacidad de reacción para neutralizar o corregir en favor de los objetivos originales los efectos nocivos de esos factores imprevisibles. En cualquier caso, las circunstancias que se enfrenten tendrán que contar siempre con el entendimiento entre las parte involucradas.

Un modo singular empleado en Europa como reactivador y atractivo urbano han sido los centros de educación ambiental. Fonseca analiza nueve casos distribuidos en Bélgica, España, Francia, Holanda, Inglaterra y República Checa, en los que se ha puesto especial interés en la sustentabilidad. Un rasgo común que reúne esta selección de experiencias europeas es que el espacio natural se sitúa en un borde urbano y señala el tránsito de una arquitectura concebida como protección frente a las inclemencias de la naturaleza hacia una naturaleza frágil que debe ser protegida.

En tiempos que se avizoran como una nueva era geológica, el antropoceno, la acción humana ha provocado cambios de escala geológica sobre el planeta y como reacción nos encontramos ante un ideal de vida urbana emergente que fomenta la naturalización de la vida en la ciudad. La búsqueda del ocio y la ecología se canaliza en diversas acciones de reciclaje de la ciudad a través de modelos de ocupación de áreas de relleno o solares mediante proyectos sociales efímeros, huertos ecológicos y de ocio. Otro ejemplo, son las centrales energéticas de barrio que, al mismo tiempo, al igual que los centros en torno al ciclo del agua, son demostradores y divulgadores. Centros de interpretación y difusión de cultura sostenible son fundamentales para la visibilidad de una cultura verde.

Esta mirada a los centros de interpretación, como señala Fonseca, es una vía fructífera en tanto que sirvan de puente entre lo urbano y lo natural, a la vez que refuercen su protección controlada y sean activadores de la conciencia social medioambiental. En otro orden, por ser arquitecturas pasivas en equilibrio con su entorno y respondiendo a las especificidades del clima, son laboratorios y demostradores de principios de ecología, eficiencia energética y uso de energías renovables; son modelos replicables a escala urbana.

El Campillo, uno de los centros de educación ambiental que cita Fonseca, del que también es autor del proyecto, muestra un interesante ejemplo de la recuperación de paisajes modificados por el uso industrial a través de una segunda naturalización. El lugar ha sido zona de extracción de áridos para la construcción de hormigones, por tratarse de graveras naturales de ribera. En época reciente, agotado el recurso, se produjo una inundación natural de estos grandes vacíos surgiendo lagunas en las que, finalmente hoy, gracias al debido tratamiento, recalan aves migratorias que hacen el recorrido desde el norte de Europa hacia África. Se trata de la cabecera del Parque Regional de Sureste donde confluyen las cuencas de los ríos Jarama y Manzanares, ejes fundamentales en el mapa de los recursos hídricos de la Comunidad de Madrid. Una situación de gran riqueza y complejidad que puede considerarse un ejemplo muy destacado en su género.

Por su parte, la mirada histórica que aporta Sahady sobre las ciudades iberoamericanas, pone en evidencia el contrapunto de las preocupaciones en este lado del mundo, donde la discontinuidad de los desarrollos y planes urbanos se cruza con el reiterado dilema de la confrontación entre lo nuevo y lo antiguo, que dejan constantemente el amargo sabor de la decepción por las propuestas inconclusas. Una situación que hace creer que se actúa siempre sobre un erial o se está en permanente experimentación. Se revisan los casos de Quito, La Habana, Buenos Aires y Salvador de Bahía, referentes contemporáneos de las acciones emprendidas para la recuperación de cascos históricos y revitalizarlos.

En Quito, la gestión para proteger y desarrollar el casco histórico integró a las autoridades y a los ciudadanos, en parte, su éxito se debió a este aserto. El logro no estuvo exento de dificultades en el terreno del financiamiento y los acuerdos que hubo de obtenerse con el gremio del transporte.

La declaratoria de La Habana como Patrimonio de la Humanidad en 1981, marcó el inicio de una notoria recuperación de la ciudad histórica desde una nueva perspectiva. Uno de los propósitos fue mantener a los residentes y crearles puestos de trabajo. Las intervenciones han resultado positivas, reactivando la zona como destino turístico, e incorporando, asociadas al reavivamiento, otras actividades que redundan en la vitalidad del lugar y en su sostenimiento económico.

El casco histórico de Buenos Aires era víctima del paulatino abandono producido por la migración de las actividades terciarias, en esto se distinguía de los casos anteriores. En la década de 1990, coincidiendo con el interés internacional por la preservación del ambiente y del patrimonio, se inicia una serie de acciones tendientes a la recuperación de edificios y bodegas portuarias, junto con otras de menor notoriedad como la recuperación de paseos. El uso de las áreas rehabilitadas fueron los servicios y la vivienda. Como en los casos anteriores, la implementación de marcos regulatorios y normativos ha sido clave para conducir estos procesos.

La ciudad de Bahía caracteriza a las ciudades iberoamericanas en relación a la recuperación de los centros históricos: empobrecimiento 
del núcleo central, emigración de ocupantes acomodados y abandono del uso residencial, entre otros fenómenos deteriorantes. Entre 1960 y 1970, se pusieron en marcha una serie de restauraciones y reciclajes en vista a un desarrollo turístico, luego se crearon programas de carácter social que ocuparían antiguas casonas reconvertidas. Por último, en la década de 1990, incorporando agrupaciones musicales de éxito internacional, se instituyó el barrio histórico como un gran centro de equipamiento cultural. No sin antes haber invertido la autoridad una fuerte suma de dinero en indemnizar a los residentes para que migraran a otras áreas de la ciudad. La estrategia no surtió los efectos esperados, luego de un breve período de revitalización, sobrevino el decaimiento y el retroceso de lo obtenido. Una institución creada ad hoc ha puesto en marcha un nuevo intento estratégico del que aún no se pueden medir sus resultados.

Un conjunto de estrategias de intervención y regeneración que, tal como es sugerido por Muñoz y Sánchez, permiten el desarrollo de un ejercicio proyectual más consciente, reconociendo los valores de las preexistencias y reflexionando en torno a las posibilidades de intervención. En este contexto, la valoración patrimonial supone una mirada activa que estimula nuevas metodologías de conservación, con el debido compromiso de responsabilidad ética que tales acciones sugieren. Como es planteado por los autores, una intervención consciente implica la construcción de un debido soporte técnico, histórico y conceptual que valide cada una de las acciones emprendidas.

\section{CLAVES DE LA REGENERACIÓN}

En las principales ciudades europeas se están elaborando mapas de vulnerabilidad en los que se pretende identificar, clasificar y establecer prioridades de intervención regeneradora. La pirámide de población muestra un envejecimiento y una integración no lograda de ciudadanos europeos de segunda y tercera generación, que conlleva a graves y frecuentes situaciones de exclusión. Y las barriadas, que antaño fueron periferia de las ciudades, con el crecimiento de las ciudades en algunos de los casos se han convertido en áreas de oportunidad.

En relación a la vivienda social existe un conflicto: la defensa de la vivienda en su función social, entendiendo que es un derecho básico de los ciudadanos, se enfrenta a la dificultad de lograr la viabilidad económica. La iniciativa pública en la actividad rehabilitadora parece haber llegado a su fin. Al respecto, se perfila un modelo que se apoya en la iniciativa privada, incluso en países que históricamente han tenido un parque de viviendas mayoritariamente de alquiler, como Holanda. Los procesos de regeneración urbana en Europa se están empezando a canalizar en buena medida a través de conciertos de financiación públicoprivado con una cada vez menor intensidad de lo público. El coste de la rehabilitación requiere mecanismos de financiación que contemplan múltiples entradas de recursos: fondos públicos, estatales y europeos en tendencia decreciente, retornos económicos del ahorro energético y la consideración de una plusvalía verde que se estima entorno al $2 \%$ y al $5 \%$ de incremento de valor de la vivienda rehabilitada.

El agotamiento de los recursos energéticos fósiles y la dependencia energética del exterior son cuestiones clave para Europa. El cumplimiento de los objetivos de reducción de emisiones de gases de efecto invernadero, la reducción de la demanda energética y el empleo de fuentes de energía renovables constituyen las claves esenciales que vertebran las políticas energéticas de la Unión Europea. La conversión de las ciudades en ciudades bajas en carbono, incluye previsiones que afectan en importante medida a los requisitos de eficiencia energética, como llave para canalizar los fondos europeos hacia las ciudades.
Los proyectos pilotos replicables que se presentan en este número, son modelos urbanos de mayor compacidad con objeto de evitar la expansión urbana y el impacto de nuevas infraestructuras. A través de la mezcla tipológica se busca la mejora social a través de la mixtura de clases. De las primeras propuestas de regeneración con realojo sin retorno de la población, el ideal de las últimas intervenciones (es el caso de Europarei en Holanda), considera un cien por cien de realojo en el barrio rehabilitado.

¿Qué alcance teórico pueden tener las estrategias de las que dan cuenta los artículos que aquí se presentan para la reflexión sobre la ciudad? ¿Qué está significando la regeneración de las ciudades? ¿̇on un mea culpa en relación a esas áreas que se deterioraron por una sobreexplotación, y que ahora necesita revalorizarse? Desde la ciudadanía también es posible reconocer cambios, por ejemplo, respecto al patrimonio. El ciudadano no ha dependido de los profesionales del área para empezar a poner en valor sus barrios, sus calles y para organizarse en defensa de estos objetivos. Interesa a los investigadores comprender los mecanismos de transformación de abajo hacia arriba, bottom up, y se promueven estudios de modelos de planificación en base a los resultados de la satisfacción medida de los habitantes. En Chile, por ejemplo, hay un día del año que ha sido declarado conmemorativo del patrimonio. Para la ocasión, edificios públicos abren sus puertas para ser visitados, y mostrados, normalmente por estudiantes. En este contexto, es destacable que residentes en lugares de viviendas populares que fueron vapuleados durante la dictadura, identifican sectores en sus propias poblaciones a los que le dan valor patrimonial. Todo parece indicar que se abren nuevas perspectivas para entender las ciudades, intervenir en ellas y considerar a los habitantes de diversas nuevas maneras. 